This document is published in:

Materials and Design, Vol. 60 (2014), pp. 628-636

DOI: http://dx.doi.org/10.1016/j.matdes.2014.04.019

(C) 2014 Elsevier Ltd. 


\section{Accepted Manuscript}

Study of the Properties of Low-cost Powder Metallurgy Titanium Alloys by 430 Stainless Steel Addition

L. Bolzoni, E. Herraiz, E.M. Ruiz-Navas, E. Gordo

PII: S0261-3069(14)00287-8

DOI: http://dx.doi.org/10.1016/j.matdes.2014.04.019

Reference: JMAD 6410

To appear in:

Materials and Design

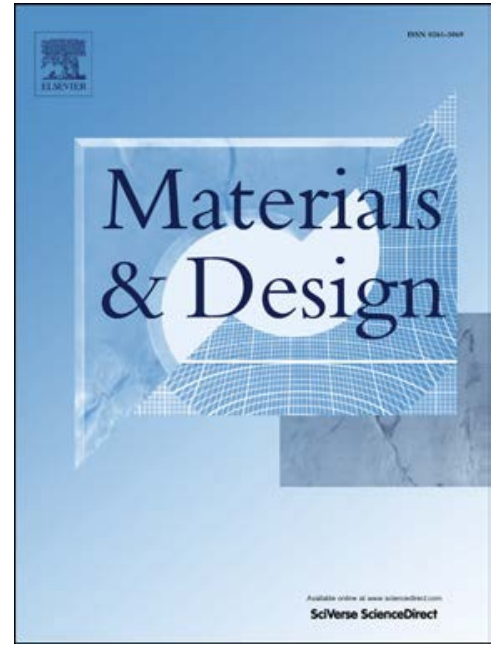

Received Date: $\quad 13$ February 2014

Accepted Date: $\quad 6$ April 2014

Please cite this article as: Bolzoni, L., Herraiz, E., Ruiz-Navas, E.M., Gordo, E., Study of the Properties of Lowcost Powder Metallurgy Titanium Alloys by 430 Stainless Steel Addition, Materials and Design (2014), doi: http:// dx.doi.org/10.1016/j.matdes.2014.04.019

This is a PDF file of an unedited manuscript that has been accepted for publication. As a service to our customers we are providing this early version of the manuscript. The manuscript will undergo copyediting, typesetting, and review of the resulting proof before it is published in its final form. Please note that during the production process errors may be discovered which could affect the content, and all legal disclaimers that apply to the journal pertain. 


\title{
Study of the Properties of Low-cost Powder Metallurgy Titanium Alloys by 430 Stainless Steel Addition
}

\author{
L. Bolzoni*, E. Herraiz, E.M. Ruiz-Navas, E. Gordo \\ Department of Materials Science and Engineering, University Carlos III of Madrid, \\ Avda. de la Universidad, 30, 28911 Leganes, Madrid - Spain \\ *bolzoni.leandro@gmail.com, 1bolzoni@ing.uc3m.es, +34916249482
}

\begin{abstract}
Titanium is a lightweight metal with an outstanding combination of properties which make it the material of choice for many different applications. Nonetheless, its employment at industrial level is not widespread due to higher production costs with respect to competitor metals like steel and aluminium. In this work the production of low-cost titanium alloys is attempted by combining the utilisation of a powder metallurgy process and cheap alloying elements (i.e. commercial 430 stainless steel powder optimised for the powder metallurgy industry). Low-cost titanium alloys are fabricated by blending elemental titanium with stainless steel. The behaviour of the powders as well as that of the sintered materials are analysed and compared to that of a master alloy addition Ti6Al4V alloy. The produced low-cost titanium alloys show comparable properties to both wrought and powder metallurgy titanium alloys and, therefore, they are proposed as an alternative to obtain structural component made out of titanium alloys.
\end{abstract}

Keywords: low-cost titanium alloy, titanium powder metallurgy, blending elemental, homogeneous microstructure

\section{Introduction}

Titanium and its alloys have an excellent combination of specific mechanical properties and corrosion resistance higher than both steels and aluminium alloys but they are currently barely used in industrial application rather than in highly demanding sectors (i.e. aeronautical, military and biomedical) [1]. The main inconvenience that hinders the selection of titanium in the design of an engineering part for most industrial applications is the high cost of the final product compared to its competitors. The high cost is strictly related to all the production steps, from the 
extraction and processing to the fabrication into components or structures and it is due to the inherent characteristics of titanium, like the high affinity for interstitials (i.e. oxygen, nitrogen, carbon and hydrogen) and the high reactivity with atmosphere which increases the extraction and fabrication costs, as well as the poor machinability associated with the relative low thermal conductivity of titanium alloys. A detailed analysis and breakdown of the fabrication costs in comparison to other structural metals was done by Froes. et al. [2] where it is emphasised that the cost reduction for titanium components can come from either a reduction in the cost of production of the metal itself or from creative techniques for the fabrication of final components. Even though of this critical scenario, the transport industry and, in particular, the automotive sector, are showing interest in titanium alloys, as their use could reduce the consumption of oil and the pollution of vehicles.

The implementation of powder metallurgy (PM) techniques for the production of titanium products would provide various advantages over the conventional metallurgy of titanium which can be summarised in four points. 1) PM are near-net-shape methods and, therefore, characterised by higher yield of materials and limited machining operations which results in avoiding looses of the high-priced metal. 2) The temperatures at which titanium and its alloys are sintered are lower than the melting point of the metal and this leads to a significantly reduction of the reaction between titanium and production tools such as crucibles and moulds and limits interstitials pick-up. 3) Alloy composition limitation dictated by density difference (segregation) between the alloying elements and titanium, which is a typical feature of melted and solidified alloys, is prevented by using PM techniques. 4) A lot of attention and a great effort have been placed by the scientific community in the development of new extraction processes whose main product is metal titanium powder which could be directly used by the existing titanium powder metallurgy industry. Summarising, the success on the development of low-cost titanium alloys seems to be related to the right selection of the PM process, the proper selection of the processing conditions and also to a good choice of the alloying elements.

On the one side, iron will be an ideal candidate for the development of less expensive titanium alloys because its cost is significantly lower in comparison to other alloying elements such as vanadium, niobium, or tantalum used to stabilise the beta phase [3]. On the other side, iron is heavier than titanium and, therefore, tends to settle and the Ti-Fe binary phase diagram is characterised by the presence of eutectic reactions [4] which lead to the formation of 
intermetallic phases which brittle the material. Nonetheless, the formation of these intermetallics can be controlled to some extent during processing. Consequently, some iron-alloyed titanium alloys can be found at commercial level like the TIMETAL low cost beta (LCB, Ti-1.5Al-5.5Fe$6.8 \mathrm{Mo}$ ) and $\mathrm{Ti}-5 \mathrm{Al}-2.5 \mathrm{Fe}$. Nevertheless, because the titanium market is still mainly driven by the aerospace industry, the greatest effort when developing titanium alloys with iron as alloying elements was concentrated in the conventional metallurgy route [5-7]. When it comes to PM, it is in the understanding of the authors that very few studies are available in the literature $[8,9]$ because the scientific community mainly focused on the research of composition of wrought alloys [10-16].

In this work low-cost titanium alloys are targeted and developed by the simultaneous employment of the simplest PM method (i.e. cold uniaxial pressing and vacuum sintering) in combination with cheaper alloying elements with respect to vanadium, a typical element used in titanium alloy to stabilise the body-centred cubic titanium phase ( $\beta$ ). Specifically, a commercially available iron and steel PM industry optimised 430 stainless steel powder is used to add iron and chromium (beta stabilisers) to elemental titanium.

\section{Experimental Procedure}

\subsection{Raw Materials}

The staring materials for the development and production of low-cost titanium alloys were a hydride-dehydride ( $\mathrm{HDH})$ elemental titanium powder supplied by $\mathrm{GfE} \mathrm{GmbH}$ and a gas atomised AISI 430 LHC ferritic stainless steel powder bought from Sandvik. Basic characteristics such as density, particle size and chemical analysis of these starting powders are reported in Table 1 whereas the morphology is shown in Figure 1 by means of SEM images. From the data shown in Table 1 it can be seen that the two starting powders are characterised by an important difference in terms of density but this is not a concern because the segregation of heavy alloying elements typical of conventional metallurgy is prevented when using PM methods as explained in the introduction. Concerning the particle size distribution, elemental titanium and 430 LHC stainless steel powders have a maximum size of $75 \mu \mathrm{m}$ and $22 \mu \mathrm{m}$, respectively. The much lower particle size of the steel powder chose to introduce the alloying elements should favour the diffusion of iron and chromium towards titanium rather than the 
interdiffusion or the self-diffusion of titanium. Regarding the chemical composition data reported in Table 1, what it has the be highlighted for the titanium powder is that oxygen content is about 0.31 wt. $\%$ and nitrogen and carbon are lower than 0.05 wt. $\%$ and 0.08 wt. $\%$, respectively, which permits to identify it as commercially pure titanium grade 3 [17]. In the case of the stainless steel powder, all the elements that composed the alloy are beta stabilisers ( $\mathrm{Fe}, \mathrm{Cr}, \mathrm{Si}$ and $\mathrm{Mn}$ ) with the exception of carbon which is an alpha stabiliser. The morphology of the powders is a direct consequence of their production method. Specifically, elemental titanium powder has an irregular morphology (Figure $1 \mathrm{a})$ because a comminution process was used to produce it. That is because in the HDH process, titanium is made brittle by the adsorption of hydrogen, milled and finally heat-treated under vacuum to remove hydrogen. In the case of the stainless steel powder, its morphology is spherical (igure $1 \mathrm{~b}$ ) because it was fabricated by means of an atomisation process. Moreover, it can be noticed that some of the powder particles are, actually, characterised by an elongated shaped rather then a perfect spherical shape. The irregular morphology of elemental titanium, which constitutes the mayor element of the alloys developed, guarantees the successful compressibility of the low-cost titanium alloys powders by means of the conventional, and well established in industry, cold uniaxial press process.

\subsection{Preparation and characterisation of powders}

The design of the low-cost titanium alloys was done based on a previous work [3] where elemental iron was added and, thus, an equivalent addition of iron in the 5-7 wt.\% range was chosen. The amount of stainless steel powder to be added for each one of the low-cost titanium alloy was calculated considering the formula proposed by Molchanova to take into account the total effect of the beta stabilising elements [18]. Reconsidering the effect of the chemical composition of the 430 LHC stainless steel, iron (which is the base) and chromium (the mayor alloying element) will determine the stabilisation of the beta phase whilst the effect of the other alloying elements (i.e. $\mathrm{Si}, \mathrm{Mn}$ and $\mathrm{C}$ ) can probably be disregarded due to their actual very low percentage in the final composition of the low-cost titanium alloys powders. The Ti-5Fe and Ti$7 \mathrm{Fe}$ powders were produced by mixing the appropriate ratio of elemental and 430 powders in a Turbula mixer for 30 minutes. The density of the blended powders was measured with an AccuPyc 1330 Helium pycnometer. The values obtained were kept as the theoretical density of the alloys and were used to calculate the relative density of the sintered materials. A laser beam 
Mastersizer 2000 particle size analyser was used to measure the particle size distribution of the blended powders whilst their oxygen and nitrogen contents were determined on the base of the ASTM: E1409 standard by means of an appositely calibrated LECO TC500 equipment.

\subsection{Manufacturing of alloys by pressing and sintering}

Initially, the compressibility (ASTM: B331) study for each of the two powders prepared was carried out by shaping rectangular samples (ASTM: B528) applying a uniaxial pressure in the range between $300 \mathrm{MPa}$ and $700 \mathrm{MPa}$. Moreover, the same specimens were used to measure the green density $\left(\rho_{g}\right)$ of the alloys. The performance of the Ti-5Fe and Ti-7Fe powders during consolidation was compared to that of a Ti6Al4V powder produced by master alloy addition [19]. From the results of this characterisation the compaction pressure of $700 \mathrm{MPa}$ was finally chosen to press the samples to be sintered. Before to proceed with the sinterability study, differential thermal analysis (DTA) of each powder was carried out in a SETSYS Evolution 16/18 equipment. Specifically, the conditions adopted for DTA experiments were: maximum temperature of $1400^{\circ} \mathrm{C}$, dwell time of 15 minutes at maximum temperature,, heating and cooling rates of $10^{\circ} \mathrm{C} / \mathrm{min}$ and inert atmosphere guaranteed by a constant flow of Argon of $40 \mathrm{ml} / \mathrm{min}$. Sintering of the green specimens was done by batches in a high vacuum tubular furnace. During sintering minimum level of vacuum of $10^{-5}$ mbar was guaranteed and the heating and cooling rates were set to $5^{\circ} \mathrm{C} / \mathrm{min}$. In relation to the sintering parameters, the time was set to 60 minutes whilst three temperatures were selected: $900^{\circ} \mathrm{C}, 1200^{\circ} \mathrm{C}$ and $1300^{\circ} \mathrm{C}$. The lowest sintering temperature considered $\left(900^{\circ} \mathrm{C}\right)$ was chosen to study and check the diffusion of the alloying elements towards the titanium matrix whereas the other two temperatures are conditions generally employed to sinter titanium and its alloys.

\subsection{Characterisation of Pressed and Sintered Low-cost Titanium Alloys}

The quantification of the effect of the sintering step on the geometry of the samples was done by considering the dimensional change. The density of the sintered specimens $\left(\rho_{s}\right)$ was determined by the Archimedes' method whilst the relative density $\left(\rho_{r}\right)$ was calculated using as theoretical value $\left(\rho_{t h}\right)$ the data obtained from helium pycnometry as indicated previously. The densification parameter $(\Psi)$, calculated using equation 1 , was taken into account to quantify the phenomena that govern the sintering step: 


$$
\Psi=\frac{\rho_{s}-\rho_{g}}{\rho_{t h}-\rho_{g}} * 100[\%]
$$

Samples were grinded with SiC paper of different granulometry, polished with silica gel and etched with Kroll reagent to reveal the microconstituents prior to proceed with the microstructural analysis by scanning electron microscopy (SEM, Philips XL-30). This same equipment, which is provided with an EDS detector, was also used to analyse the diffusion of the alloying elements and to check the chemical homogeneity of the sintered materials. The identification of the phase composing the sintered alloys was done by means of a X-ray difractometer (Philips X'Pert-MPD) in the $2 \theta$ range from $20^{\circ}$ to $120^{\circ}$ using goniometer step of $0.02^{\circ}$ and step time of $1.2 \mathrm{~s}$. Because interstitials, especially oxygen and nitrogen, have a significant effect on the mechanical behaviour of titanium and its alloys [20], their contents was measured using the same equipment (LECO TC500) employed for the analysis of the powders. The flexural properties of the samples were measured by means of three-point bending tests (ASTM: B528) using a MicroTest machine. Finally, HV30 hardness measurements were carried out using a Wilson Wolpert DIGI-TESTOR 930 universal tester. The results of the characterisation of the sintered alloys are compared to those of a Ti6Al4V powder produced by master alloy addition [21].

\section{Results and Discussion}

\section{$\underline{\text { 3.1 Characterisation of Low-cost Titanium Alloys Powders }}$}

As indicated in the experimental procedure, the low-cost titanium alloys powders were produced by mixing elemental titanium powder and 430 LHC stainless steel powder in the proper ratio to obtain the final equivalent composition of Ti-5Fe and Ti-7Fe. The features (density, particle size distribution and interstitials contents) of these two powders are shown in Table 2.

As it can be seen in Table 2, the density of the blended powders increases with the increment of the alloying elements, which is the expected behaviour since steel is heavier than titanium. It is worth remembering that these values were used to calculate the relative density of the sintered products. From the results of the particle size distribution done on the mixed powder, both of 
them have a maximum particle size lower than $90 \mu \mathrm{m}$ which is mainly dictated by the original particle size of the elemental titanium powder used to fabricate them. The determination of the amount of interstitials present in the mixed powder permits to highlight that the addition of the 430 stainless steel powder does not practically change the amount of oxygen dissolved whilst it leads to some more higher nitrogen content to the value indicated by the supplier (Table 1). This slight increment of nitrogen is most probably due to the handling of the powder which favours the adsorption of nitrogen molecules into the surface of the powder particles.

The results of the compressibility study and the variation of the green strength versus the compaction pressure are presented in Figure 2.

From Figure 2, the compressibility of the powders increases with the increment of the compaction pressure, which is the expected behaviour for cold uniaxial pressed powders. Moreover, there is not a significant difference between the Ti-5Fe and the Ti-7Fe powders indicating that the amount of 430 stainless steel powder added does not affect the compressibility. Nonetheless, the green densities obtained for the low-cost titanium alloys powders is lower than the values of the Ti6Al4V alloy (produced by blending elemental titanium with an Al:V master alloy with irregular morphology) [19]. The behaviour shown in Figure 2 indicates that the presence of the spherical 430 stainless steel powder produces a loss of compressibility which is due to the spherical morphology of the steel powder added to the irregular titanium powder. When considering the results of the green strength (Figure 2), the two low-cost titanium alloy powders have similar trend and comparable values even though the Ti$5 \mathrm{Fe}$ powder performs a little bit better than the Ti-7Fe powder. Surprisingly, the low-cost titanium alloy powders present better green strength with respect to the master alloy addition Ti6Al4V powder despite the lower green density. This is most probably due to the fact that the steel allows a better mechanical interlocking of the powder particles, which is the main factor determining the strength of green PM parts [22].

Green parts pressed at $700 \mathrm{MPa}$ were used the study the thermal behaviour of the alloys by means of DTA analyses and the results are shown in Figure 3.

From the analysis of the DTA heating curves shown in Figure 3, it can be seen that the only thermal reaction detected is an endothermic peak around $900^{\circ} \mathrm{C}$. By means of the dedicated software, the onset temperature and the peak temperature for both powders were found to be near $818^{\circ} \mathrm{C}$ and $887^{\circ} \mathrm{C}$, respectively. This endothermic reaction is the allotropic transformation of 
elemental titanium from the hexagonal alpha phase $(\alpha)$ to the body-centred cubic beta phase $(\beta)$. It is well known that iron is an eutectic beta stabiliser element when added to titanium [23], and from the Ti-Fe binary phase diagram [4] there are two intermetallics ( $\mathrm{TiFe}$ and $\mathrm{TiFe}_{2}$ ) which can be formed and are thermodynamically stable at room temperature. Nevertheless, from the results of the DTA curves shown in Figure 3 it is clear that by adding the iron by means of the 430 LHC stainless steel powder the formation of these intermetallics is prevented. Moreover, it can be noticed that the alpha to beat transformation takes place at the one corresponding to elemental titanium (i.e. $882^{\circ} \mathrm{C}$ ) although the presence of a beta stabiliser element which should modify the phase transformation temperatures (i.e. alpha and beta transus). This behaviour is due to the fact that iron is not dissolved yet inside the titanium matrix and, thus, in this case it does not influence the parameters obtained. A similar behaviour was detected when producing titanium alloys by master alloy addition powder [21].

\subsection{Characterisation of Sintered Low-cost Titanium Alloys}

Figure 4 shows the variation of the volume of the green samples and the densification (equation 1) with the sintering temperature.

As it can be seen from the volume variation (Figure 4), during sintering the samples undergo shrinkage, which increases with the sintering temperature from $4 \%$ at $900^{\circ} \mathrm{C}$ to approximately $18 \%$ at $1300^{\circ} \mathrm{C}$. It is worth mentioning that the shrinkage of the specimens was quite uniform along the three dimensions: length, width and thickness. When comparing the behaviour of the two low-cost titanium alloys powders, the Ti-7Fe alloy has slightly higher volume variation compared to the Ti-5Fe powder with the exception of the lowest sintering temperature studied (i.e. $900^{\circ} \mathrm{C}$ ). Since the two powders reach the same green density when pressed at $700 \mathrm{MPa}$ (Figure 2), the somewhat higher shrinkage of the Ti-7Fe alloy is due to the greater amount of alloying elements (430 stainless steel powder particles) which diffuse towards the titanium matrix. The densification of the samples (Figure 4) increases along with the processing temperature and the Ti-7Fe alloy shows a little but higher densification than the $\mathrm{Ti}-5 \mathrm{Fe}$ alloy. However, the most important point is that there is quite an important gap between the densification values of the specimens sintered at $900^{\circ} \mathrm{C}$ with respect to the values for samples processed at higher temperatures. Specifically, the densification at $900^{\circ} \mathrm{C}$ is around $20 \%$, which is due to small differences in terms of density between the green and sintered samples. This low 
value seems to indicate that at $900^{\circ} \mathrm{C}$ most of the thermodynamic energy of the system is spent for the diffusion and homogenisation of the alloying elements instead of in the densification of the green compacts. Conversely, the densification becomes more important or more pronounced at higher temperatures suggesting that the diffusion of the alloying elements is completed. This is further confirmed by the fact that the Ti-7Fe alloy, which has higher percentage of alloying elements, sintered at $900^{\circ} \mathrm{C}$ is characterised by a lower densification in comparison to the Ti-5Fe alloy.

The variation of the relative density of the sintered samples as a function of the processing temperature is displayed in Figure 5.

As it could have been expected from the trends of the volume variation and of the densification, the relative density (Figure 5) of the two low-cost titanium alloys increases when increasing the sintering temperature. This is the typical behaviour of PM parts where a higher processing temperature, generally, induces the elimination of the interparticles boundaries and, consequently, to the reduction of the residual porosity. In particular, the relative density ranges from $84 \%$ for specimens sintered at $900^{\circ} \mathrm{C}$ to $94 \%$ for samples processed at $1300^{\circ} \mathrm{C}$. By comparing the trend of the two low-cost titanium alloys, it can be seen that the Ti-7Fe alloy reaches higher final relative density than its counterpart (Ti-5Fe alloy). Moreover, the Ti6A14V alloy always reaches higher relative density values with respect to the low-cost titanium alloys although the gap between the alloys becomes smaller with the increment of the sintering temperature. This gap in terms of relative density is most probably due to the combined effect of better compressibility (i.e. higher green density) of the Ti6Al4V powder and longer processing time used to sintered it ( $2 \mathrm{~h}$ versus $1 \mathrm{~h}$ ). Nonetheless, the final relative density achieved in both low-cost titanium alloys sintered at $1300^{\circ} \mathrm{C}$ (i.e. 94\%) is a common value obtained when processing titanium and its alloys by means of the conventional powder metallurgy route [2426].

The results of the microstructural analysis carried out to study the diffusion of the alloying elements towards the titanium matrix and to characterise the phases that compose the alloy are shown in Figure 6.

As it can be seen from Figure 6 a) and b), the sintering of the low-cost titanium alloys at very low processing temperature (i.e. $900^{\circ} \mathrm{C}$ ) leads to quite homogeneous microstructure even though very few bright particles of approximately 5-10 $\mu \mathrm{m}$ of 430 LHC stainless steel powders are 
visible in the microstructure. The microstructure of these samples is composed by alpha grains due to the elemental titanium powder and $\alpha+\beta$ lamellae due to the $\beta$-stabilising effect of both iron and chromium. Actually, the diffusion of these alloying elements towards the titanium matrix seems to be quite efficient because, as indicated before, their distribution is relatively homogeneous. This is due to the fact that the diffusion rate of iron towards titanium is almost two orders of magnitude higher than titanium to iron [27, 28]. Another important feature of the microstructure of the samples sintered at $900^{\circ} \mathrm{C}$ is the residual porosity, whose volumetric percentage is in agreement with the relative density data shown in Figure 5. Porosity is mainly irregular in shape and interconnected due to poor densification of the materials. Consequently, most of the interparticle boundaries are still clearly visible in the microstructure. The fact that at this processing temperature the low-cost titanium alloys do not undergo a significant densification but the thermal energy is invested in the diffusion and homogenisation of the alloying elements was already deduced from the data plotted in Figure 4. An increment of the sintering temperature to $1200^{\circ} \mathrm{C}$ and $1300^{\circ} \mathrm{C}$ leads to the complete diffusion of the alloying elements and the microstructure is completely uniform. Precisely the microconstituents of the low-cost titanium alloys are primary alpha grains and $\alpha+\beta$ lamellae. Nevertheless, the most important point is that there is not the formation of any intermetallic between titanium and iron which could lower mechanical performances of these low-cost titanium alloys in agreement with the DTA results (Figure 3). When considering the residual porosity of Ti-5Fe and Ti-7Fe sintered at a temperature equal or greater than $1200^{\circ} \mathrm{C}$, it can be seen that some residual pores are still present in the microstructure where these pores are mainly spherical in shape. Nevertheless, the total amount of porosity visible in the micrographs reported in Figure 6 seems to be lower in comparison to the value expected from the relative density data. By the comparison of the micrograph of the same material processed at different temperatures (e.g. Figure $6 \mathrm{c}$ vs. Figure 6 e), it can be noticed that the increment of the sintering temperature leads to grain growth which is especially highlighted by the size of the prior beta grains. Semi-quantitative EDS analysis was carried out in the sintered low-cost titanium alloys samples and the results are reported in Table 3. It is worth mentioning that the data shown in Table 3 are representative of values taken in different analyses done in the samples sintered at $1200^{\circ} \mathrm{C}$ and $1300^{\circ} \mathrm{C}$, where the complete diffusion and homogenisation of the alloying elements in the titanium matrix is guaranteed. 
Looking at the data shown in Table 3, it can be seen that the global EDS composition of the sintered low-cost titanium alloys samples is the expected although the total amount of beta stabilisers (Mo equivalent) [18] is, actually, slightly higher than 5 w.\% $\mathrm{Fe}$ and 7 wt. \% Fe equivalent. This is most probably due to the fact that EDS analysis is semi-quantitative and the final values obtained change a little bit depending on the relative amount of phases present in the zone analysed (global) or on the exact position ( $\beta$-phase). Concerning the distribution of the alloying elements, the titanium $\alpha$ phase is constituted exclusively by titanium, which is in agreement with the Ti-Fe and Ti-Cr binary phase diagrams where both iron and chromium do not have solubility in $\alpha$-titanium [4], and, therefore, iron and chromium are completely dissolved into the titanium $\beta$ phase.

To confirm the microconstituents (phases) of the low-cost titanium alloys XRD analysis was done and the results are summarised in Figure 7.

As it can be seen from the XRD pattern reported in Figure 7, the peaks detected and identified in the two low-cost titanium alloys processed using a sintering temperature equal or higher than $1200^{\circ} \mathrm{C}$ are only the hexagonal alpha titanium phase and the body-centred cubic beta titanium phase. When considering the effect of the sintering temperature for each individual alloy (Ti-5Fe or $\mathrm{Ti}-7 \mathrm{Fe}$ ), there are not important differences which can be highlighted because the relative intensity of the different peaks are similar. Conversely, when comparing the behaviour of the two alloys (i.e. amount of alloying elements or beta stabilisers), it can be noticed that the peaks of the beta titanium phase and, especially the one that correspond to the (100) plane, is, actually, the strongest for the Ti-7Fe alloy and, thus, its intensity is greater than the one of the (101) plane of the alpha titanium phase, which is the strongest peak for the Ti-5Fe alloy. This clear indicates that, as expected, the higher the amount of beta stabilisers the greater the relative amount of beta phase present in the microstructure, which could not really have been said only based on the microstructural analysis carried out at the SEM. XRD analysis further confirms that although the total amount of iron added to titanium is greater than the amount needed for the formation of $\mathrm{TiFe}_{\mathrm{x}}$ intermetallics, these compounds do not form when processing titanium alloys with a 7 wt.\% equivalent iron by means of powder metallurgy techniques.

The results of the chemical analysis carried out to measure the amount of interstitials (i.e. oxygen and nitrogen contents) are reported in Table 4. 
As it can be seen from the data of the chemical analysis shown in Table 4, there is always some interstitials pick-up during the sintering of the low-cost titanium alloys. Specifically, both oxygen and nitrogen contents increase with the processing temperature with the exception of the Ti-5Fe alloy sintered at $1200^{\circ} \mathrm{C}$ which has the highest oxygen content of all the materials considered. The contamination of the low-cost titanium alloys by interstitials is mainly due to the handling of the powder, the air trapped in the green samples and the oxygen and nitrogen molecules adsorbed onto the powder particles. Moreover, each specific value is also influenced by the fact that the sintering of the green samples is carried out discontinuously (i.e. by batches). The oxygen and nitrogen contents are important to fully understand the mechanical performances of the low-cost titanium alloys because it is well know that interstitials have a significant influence on the mechanical properties of titanium and its alloys and, in particular, they lower the ductility of the material [20].

Representative examples of the load-deflection curves determined by means of three-point bending test are shown in Figure 8.

From the load-deflection curves reported in Figure 8, the sintered low-cost titanium alloys show a completely elastic behaviour without any appreciable plastic deformation before fracture. Since the dimensions of the tested specimens are comparable, it can be seen that the higher the percentage of alloying elements (Ti-5Fe vs. Ti-7Fe), the higher the load withstood during the three-point bending test and slightly higher the total deflection of the material. Moreover, it can be seen that the load-deflection curves of the different materials studied overlap indicating that their flexural modulus is comparable. Nevertheless, the absolute value of the modulus is not reported because is highly sensitive to the geometry of the samples used and, therefore, it is not an intrinsic property of the alloys studied [29].

The mean value of the transverse rupture strength and deflection to fracture of the low-cost titanium alloys sintered at $1200^{\circ} \mathrm{C}$ and $1300^{\circ} \mathrm{C}$ are displayed in Figure 9 in comparison to the Ti6Al4V powder produced by master alloy addition [19].

From the results of the transverse rupture strength of the low-cost titanium alloys measured by

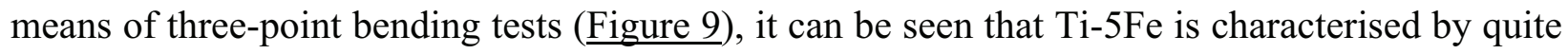
a constant strength which does not seem to be influenced by the sintering temperature. Conversely, in the case of the Ti-7Fe alloy, the flexural strength decreases with the increment of the processing temperature. The behaviour of the Ti-5Fe alloy is definitely affected by the very 
high oxygen content of the samples sintered at $1200^{\circ} \mathrm{C}$ (Table 4) which makes them less resistant under a three-point bending load. Whilst the decrement of the strength with the sintering temperature is due to the combined effect of the higher amount of interstitials dissolved by the alloy and the bigger grain size which derives from a higher processing temperature (Figure 6). Taking into account all the influencing factors, the slightly lower relative density and higher amount of interstitials but similar microstructural features of the Ti-5Fe alloy in comparison to the Ti-7Fe alloy, a clear influence from the total amount of alloying elements (i.e. beta stabilisers) cannot be extrapolated. When comparing the performance of the low-cost titanium alloys to the titanium workhorse (i.e. Ti6A14V), it can be noticed that the Ti6Al4V alloy has higher strength when sintered at $1200^{\circ} \mathrm{C}$ but somewhat lower strength when sintered at $1300^{\circ} \mathrm{C}$. Despite the differences in terms of absolute values, the trend of the transverse rupture strength with the processing temperature is similar. This behaviour is due to the compromise between the positive effect of the reduction of the residual porosity (i.e. higher relative density), the total amount of interstitials (i.e. oxygen and nitrogen) dissolved by the material and the microstructural features (i.e. alpha grain size and $\alpha+\beta$ lamellae thickness and relative amount) of each alloy sintered under different processing parameters. Independently of the influence of all these factors which make the final strength to vary in between $1150 \mathrm{MPa}$ and $1430 \mathrm{MPa}$, the flexural strength of the low-cost titanium alloys is still comparable to the value specified for wrought medical devices made out of Ti6Al4V (903-1090 MPa) and/or Ti6A17Nb (935-995 $\mathrm{MPa}$ [ [30]. Concerning the deflection to fracture, it can be seen that the general trend of the lowcost titanium alloys is exactly the same as that of the transverse rupture strength. Therefore, the deflection is quite constant for the Ti-5Fe alloy whilst it decreases for the Ti-7Fe alloy when using a higher sintering temperature. Consequently, the performance of the low-cost titanium alloys in terms of ductility as compared to the Ti6Al4V alloy is similar to the of the flexural strength although the Ti6Al4V alloy always reaches somewhat higher deflection to fracture independently of the processing parameters used. In this case, this is most probably due to the amount of oxygen and nitrogen picked-up from the low-cost titanium alloys which make them more brittle.

The variation of the Vickers hardness with the sintering temperature is presented in Figure 10. As it can be seen from the data of the Vickers hardness displayed in Figure 10, the materials become harder with the increment of the sintering temperature. This behaviour is expected 
because a higher processing temperature leads to higher relative density (as shown in Figure 5) or, in turns, lower amount of residual porosity which decreases the hardness. Regarding the values of the low-cost titanium alloys, from the hardness value it can be clearly highlight the effect of the amount of alloying elements used because the Ti-7Fe alloy is characterised by a higher hardness with respect to the Ti-5Fe alloy where the difference is around $20 \mathrm{HV}$. It has to be pointed that both Ti-5Fe and Ti-7Fe experience a greater oxygen pick up with the increment of the sintering temperature (Table 4). The influence of interstitials also balances the growth in grain size shown in Figure 6 for samples sintered at $1300^{\circ} \mathrm{C}$. This is in particular significant in the view that the Ti-5Fe alloy has lower relative density but higher interstitials contents which have very strong effect on the hardness of titanium alloys. The final hardness of the low-cost titanium alloys is, at least, comparable (Ti-5Fe) or higher (Ti-7Fe) with respect to the Ti6Al4V processed by conventional [25] and advanced [10, 12, 15, 16] techniques.

\section{Conclusions}

From the study about the production of low-cost titanium alloys by means of addition of commercially available AISI 430 LHC ferritic stainless steel powder optimised for powder metallurgy processing it can be concluded that, generally, these low-cost titanium alloys have comparable behaviour to well-developed Ti6A14V alloy produced by master alloy addition process. Specifically, the addition of the spherical stainless steel powder to titanium does not decrease significantly the compressibility and the handling of the green parts is guarantee. Moreover, the employment of this stainless steel powder prevents the formation of $\mathrm{TiFe}$ intermetallics which normally form on the base of the thermodynamic of the binary phase diagram. The final relative density and mechanical performances of the low-cost titanium alloys is directly comparable to that of the titanium workhorse alloy Ti6Al4V despite the higher amount of interstitials dissolved and, thus, these materials are promising candidates for producing cheaper titanium alloys for structural applications.

\section{Acknowledgements}

The authors want to acknowledge the financial support from the Spanish Ministry of Science through the R\&D Projects MAT2012-38650-C02-01, and from Regional Government of Madrid through the ESTRUMAT (S2009/MAT-1585) project. 


\section{References}

[1] Leyens C, Peters M. Titanium and Titanium Alloys. Fundamentals and Applications. Köln, Germany: Wiley-VCH; 2003.

[2] Froes FH, Gungor MN, Imam MA. Cost-affordable Titanium: The Component Fabrication Perspective. JOM. 2007;59:28-31.

[3] Esteban PG, Bolzoni L, Ruiz-Navas EM, Gordo E. PM processing and characterisation of Ti7Fe low cost titanium alloys. Powder Metallurgy. 2011;54:242-52.

[4] Murray JL. Phase Diagrams of Binary Titanium Alloys. 1st ed: ASM International; 1987.

[5] Lin DJ, Ju CP, Lin JHC. Structure and Properties of Cast Ti-Fe Alloys. Transactions of the American Foundrymen's Society, Vol 107. 1999;107:859-64.

[6] Holden FC, Ogden HR, Jaffee RI. Heat Treatment and Mechanical Properties of Ti-Fe Alloys. Transactions of the American Institute of Mining and Metallurgical Engineers. 1956;206:521-8.

[7] Lee DB, Park KB, Jeong HW, Kim SE. Mechanical and Oxidation Properties of Ti-xFe-ySi Alloys. Materials Science and Engineering A. 2002;328:161-8.

[8] Majima K, Hirata T, Yamamoto M, Nagai H, Shouji K. Microstructures and Tensile Properties of Hot Isostatically Pressed Ti-Fe Alloys. Journal of the Japan Institute of Metals. 1988;52:1113-20.

[9] Ivasishin OM. Cost-effective Manufacturing of Titanium Parts with Powder Metallurgy Approach. Materials Forum 2005;29:1-8.

[10] Bolzoni L, Montealegre Meléndez I, Ruiz-Navas EM, Gordo E. Microstructural Evolution and Mechanical Properties of the Ti-6Al-4V Alloy Produced by Vacuum Hot-pressing. Materials Science and Engineering A. 2012;546:189-97.

[11] Brandl E, Palm F, Michailov V, Viehweger B, Leyens C. Mechanical Properties of Additive Manufactured Titanium (Ti-6Al-4V) Blocks Deposited by a Solid-state Laser and Wire. Materials and Design. 2011;32:4665-75.

[12] Khan DF, Yin H, Li H, Qu X, Khan M, Ali S, et al. Compaction of Ti-6Al-4V Powder using High Velocity Compaction Technique. Materials and Design. 2013;50:479-83.

[13] Sun J, Yang Y, Wang D. Mechanical Properties of a Ti6Al4V Porous Structure Produced by Selective Laser Melting. Materials and Design. 2013;49:545-52. 
[14] Mahboubi Soufiani A, Karimzadeh F, Enayati MH. Formation Mechanism and Characterization of Nanostructured Ti6A14V Alloy Prepared by Mechanical Alloying. Materials and Design. 2012;37:152-60.

[15] Song B, Dong S, Zhang B, Liao H, Coddet C. Effects of Processing Parameters on Microstructure and Mechanical Property of Selective Laser Melted Ti-6Al-4V. Materials and Design. 2012;35:120-5.

[16] Holm M, Ebel T, Dahms M. Investigations on Ti-6Al-4V with Gadolinium Addition Fabricated by Metal Injection Moulding. Materials and Design. 2013;51:943-8.

[17] Boyer R, Welsch G, Collings EW. Materials Properties Handbook: Titanium Alloys. In: International A, editor. 2nd ed. Ohio, USA1998.

[18] Molchanova K. Phase Diagrams of Titanium Alloys. Translation of Atlas Diagram Sostoyaniya Titanovyk Splavov), Israel Program for Scientific Translations, Jerusalem. 1965:154.

[19] Bolzoni L, Esteban PG, Ruiz-Navas EM, Gordo E. Influence of Powder Characteristics on Sintering Behaviour and Properties of PM Ti Alloys Produced from Prealloyed Powder and Master Alloy. Powder Metallurgy. 2011;54:543-50.

[20] Finlay WL, Snyder JA. Effects of Three Interstitial Solutes (Nitrogen, Oxygen and Carbon) on the Mechanical Properties of High-purity Alpha Titanium. Journal of Metals 1950;188:27786.

[21] Bolzoni L, Esteban PG, Ruiz-Navas EM, Gordo E. Mechanical Behaviour of Pressed and Sintered Titanium Alloys Obtained from Master Alloy Addition Powders. Journal of the Mechanical Behavior of Biomedical Materials. 2012;15:33-45.

[22] Schatt W, Wieters K-P. Powder Metallurgy. Processing and Materials. Shrewsbury, UK: EPMA - European Powder Metallurgy Association; 1997.

[23] Lütjering G, Williams JC. Titanium: Engineering Materials and Processes. 1st ed. Manchester, UK: Springer; 2003.

[24] Abkowitz S, Rowell D. Superior Fatigue Properties for Blended Elemental P/M Ti-6Al-4V. Journal of Metals. 1986;38:36-9.

[25] Bolzoni L, Ruiz-Navas EM, Gordo E. Flexural Properties, Thermal Conductivity and Electrical Resistivity of Prealloyed and Master Alloy Addition Powder Metallurgy Ti-6Al-4V. Materials and Design. 2013;52:888-95. 
[26] Froes FH, Ivasishin OM, Moxson VS, Savvakin DG, Bondareva KA, Demidik AM. Costeffective Synthesis of Ti-6Al-4V Alloy Components via the Blended Elemental P/M Approach. In: TMS W, PA, editor. Symposium on TMS Symposium on High Performance Metallic Materials for Cost Sensitive Applications. Seattle, WA2002.

[27] Nakajima H, Yusa K, Kondo Y. Diffusion of Iron in a Diluted [Alpha]-Ti-Fe Alloy. Scripta Materialia. 1996;34:249-53.

[28] Nakajima H, Ohshida S, Nonaka K, Yoshida Y, Fujita FE. Diffusion of Iron in [Beta] Ti-Fe Alloys. Scripta Materialia. 1996;34:949-53.

[29] Stewardson DA, Shortall AC, Marquis PM, Lumley PJ. The Flexural Properties of Endodontic Post Materials. Dental Materials. 2010;26:730-6.

[30] Henry D. Materials and Coatings for Medical Devices: Cardiovascular. Ohio, USA: ASM International; 2009. 
Table 1. Basic characteristics of the starting powders.

\begin{tabular}{|c|c|c|c|}
\hline \multirow{2}{*}{\multicolumn{2}{|c|}{ Property }} & \multicolumn{2}{|c|}{ Material } \\
\hline & & \multirow[t]{2}{*}{ Elemental Ti } & $\begin{array}{c}430 \text { LHC stainless } \\
\text { steel }\end{array}$ \\
\hline \multicolumn{2}{|c|}{ Density $\left[\mathrm{g} / \mathrm{cm}^{3}\right]$} & & 7.57 \\
\hline \multirow{4}{*}{$\begin{array}{c}\text { Particle size } \\
\text { distribution }[\mu m]\end{array}$} & $\mathrm{D}_{\text {MAX }}$ & $<75$ & $<20$ \\
\hline & $\mathrm{D}_{10}$ & 21.45 & 3.5 \\
\hline & $\mathrm{D}_{50}$ & 45.80 & 9.0 \\
\hline & $\mathrm{D}_{90}$ & 85.01 & 16.0 \\
\hline \multirow{8}{*}{$\begin{array}{c}\text { Chemical } \\
\text { composition } \\
\text { [wt.\%] }\end{array}$} & $\mathrm{Ti}$ & 99.6 & - \\
\hline & $\mathrm{Fe}$ & 0.027 & Balance \\
\hline & $\mathrm{O}$ & 0.31 & $2-$ \\
\hline & $\mathrm{N}$ & 0.008 & - \\
\hline & $\mathrm{C}$ & 0.007 & 0.12 \\
\hline & $\mathrm{Cr}$ & - & $16-18$ \\
\hline & $\mathrm{Si}$ & - & 1.0 \\
\hline & $\mathrm{Mn}$ & $->$ & 1.0 \\
\hline
\end{tabular}

Table 2. Features of the low-cost titanium alloys powders.

\begin{tabular}{|c|c|c|c|}
\hline \multirow{2}{*}{ Property } & \multicolumn{2}{c|}{ Alloy } \\
\cline { 3 - 4 } & Ti-5Fe & Ti-7Fe \\
\hline \multicolumn{2}{|c|}{ Density [g/cm3] } & 4.68 & 4.72 \\
\hline \multirow{2}{*}{$\begin{array}{c}\text { Particle size } \\
\text { distribution [ } \mu \mathrm{m}]\end{array}$} & $D_{M A X}$ & $<90$ & $<90$ \\
\cline { 2 - 4 } & $D_{10}$ & 19.57 & 20.04 \\
\cline { 2 - 4 } & $D_{50}$ & 44.77 & 46.87 \\
\cline { 2 - 4 } & $D_{90}$ & 83.77 & 86.85 \\
\hline Chemical & $O$ & $0.32 \pm 0.03$ & $0.31 \pm 0.01$ \\
\cline { 2 - 4 } composition [wt.\%] & $N$ & $0.037 \pm 0.011$ & $0.042 \pm 0.007$ \\
\hline
\end{tabular}


Table 3. Results of the semi-quantitative EDS analysis.

\begin{tabular}{|c|c|c|c|}
\hline \multicolumn{2}{|c|}{ Composition } & \multicolumn{2}{c|}{ Alloy } \\
\cline { 3 - 4 } & & Ti-5Fe & Ti-7Fe \\
\hline \multirow{3}{*}{ Global [wt.\%] } & $C r$ & $1.11 \pm 0.36$ & $1.41 \pm 0.16$ \\
\cline { 2 - 4 } & $F e$ & $5.58 \pm 0.52$ & $6.55 \pm 0.08$ \\
\cline { 2 - 4 } & $T i$ & $93.31 \pm 0.88$ & $92.04 \pm 0.25$ \\
\hline \hline \multirow{3}{*}{$\alpha$-phase [at.\%] } & $C r$ & - & - \\
\cline { 2 - 4 } & $F e$ & - & 100 \\
\cline { 2 - 4 } & $T i$ & 100 & $1.43 \pm 0.15$ \\
\hline \multirow{3}{*}{$\beta$-phase [at.\%] } & $C r$ & $1.13 \pm 0.67$ & $6.46 \pm 1.27$ \\
\cline { 2 - 4 } & $F e$ & $6.79 \pm 2.09$ & $92.11 \pm 1.38$ \\
\cline { 2 - 4 } & $T i$ & $92.08 \pm 2.70$ & - \\
\hline
\end{tabular}

Table 4. Chemical analysis (oxygen and nitrogen contents) of the low-cost titanium alloys sintered materials.

\begin{tabular}{|c|c|c|c|}
\hline \multirow{2}{*}{ Alloy } & \multicolumn{2}{c|}{ Chemical composition } \\
\cline { 3 - 4 } & $O[w t . \%]$ & $N[w t . \%]$ \\
\hline \hline \multirow{2}{*}{ Ti-5Fe } & $1200^{\circ} \mathrm{C}$ & $0.59 \pm 0.09$ & $0.067 \pm 0.005$ \\
\cline { 2 - 4 } & $1300^{\circ} \mathrm{C}$ & $0.49 \pm 0.03$ & $0.073 \pm 0.012$ \\
\hline \multirow{2}{*}{ Ti-7Fe } & $1200^{\circ} \mathrm{C}$ & $0.41 \pm 0.01$ & $0.063 \pm 0.009$ \\
\cline { 2 - 4 } & $1300^{\circ} \mathrm{C}$ & $0.47 \pm 0.09$ & $0.069 \pm 0.006$ \\
\hline
\end{tabular}

$>$ Low-cost titanium alloys produced by adding 430 stainless steel as alloying element. $>$ The behaviour of the low-cost titanium alloys powders during shaping is analysed. $>$ The features of the microconstituents of the low-cost titanium alloys are identified. $>$ Mechanical properties of the low-cost titanium alloys are measured. 
Figure 1. SEM micrographs of the starting materials: a) hydride-dehydride (HDH) elemental titanium powder and b) gas atomised AISI 430 LHC ferritic stainless steel powder.

Figure 2. Compressibility and green strength of the low-cost titanium alloys powders compared to a Ti-6Al-4V powder produced by master alloy addition [18].

Figure 3. DTA heating curves for the low-cost titanium alloys powders.

Figure 4. Volume variation and densification $(\Psi)$ as a function of the sintering temperature for the low-cost titanium alloy powders.

Figure 5. Relative density ( $\rho r)$ as a function of the sintering temperature for the low-cost titanium alloys compared to a Ti-6Al-4V alloy produced by master alloy addition [18].

Figure 6. SEM micrographs (BSE mode) of the Ti-Fe alloys sintered at $900^{\circ} \mathrm{C}$ : a) $\mathrm{Ti}-5 \mathrm{Fe}$ and b) Ti-7Fe; at $1200^{\circ} \mathrm{C}$ : c) Ti-5Fe and d) Ti-7Fe and at $1300^{\circ} \mathrm{C}$ : e) Ti-5Fe and f) Ti-7Fe.

Figure 7. XRD pattern of the low-cost titanium alloys sintered at $1200^{\circ} \mathrm{C}$ and $1300^{\circ} \mathrm{C}$.

Figure 8. Representative examples of load-deflection curves of the low-cost titanium alloys sintered at $1200^{\circ} \mathrm{C}$ and $1300^{\circ} \mathrm{C}$.

Figure 9. Transverse rupture strength and deflection to fracture of the sintered low-cost titanium alloys in comparison to the Ti-6Al-4V powder produced by master alloy addition [18].

Figure 10. Vickers hardness as a function of the sintering temperature for the low-cost titanium alloys compared to a Ti-6Al-4V alloy produced by master alloy addition [18]. 

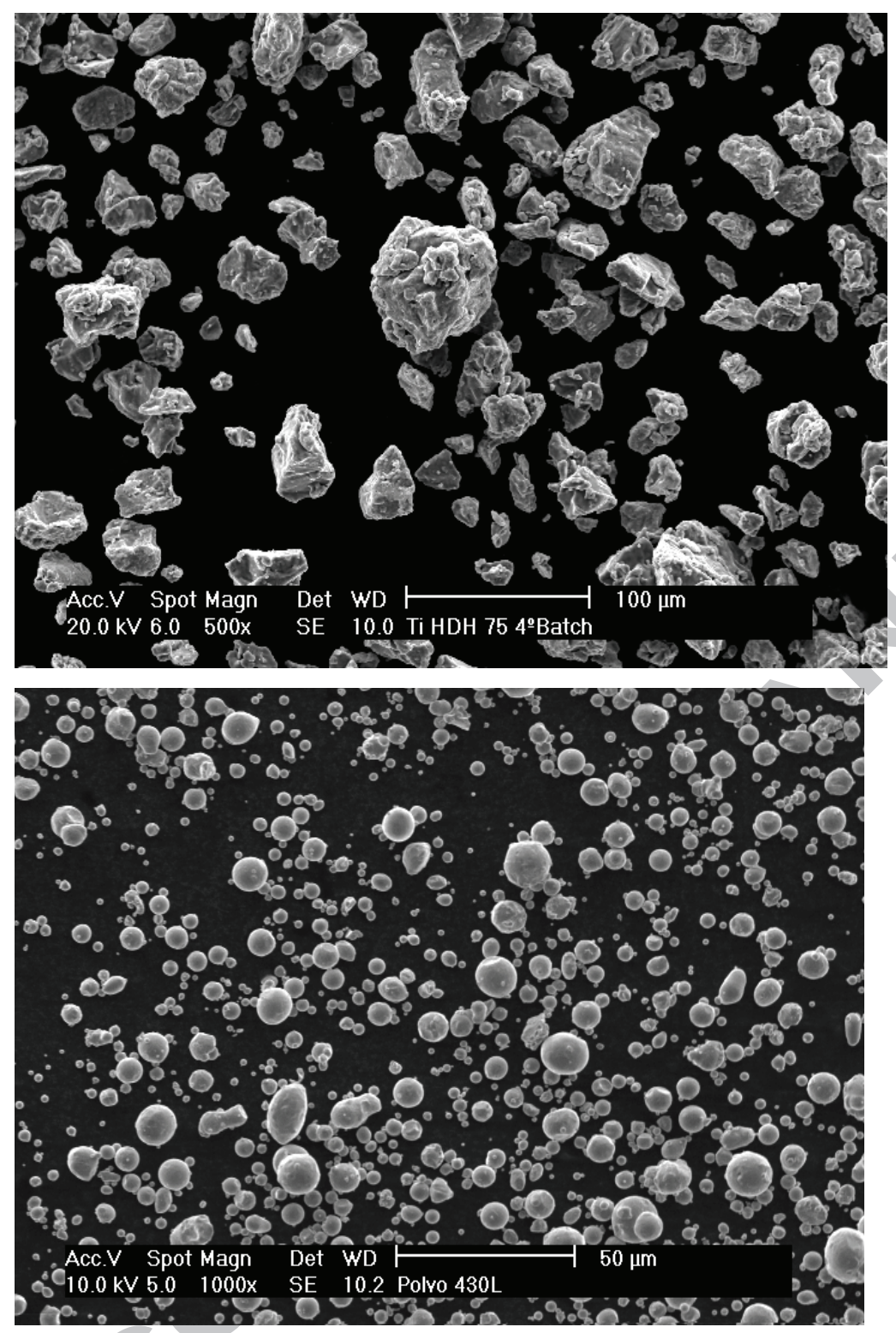


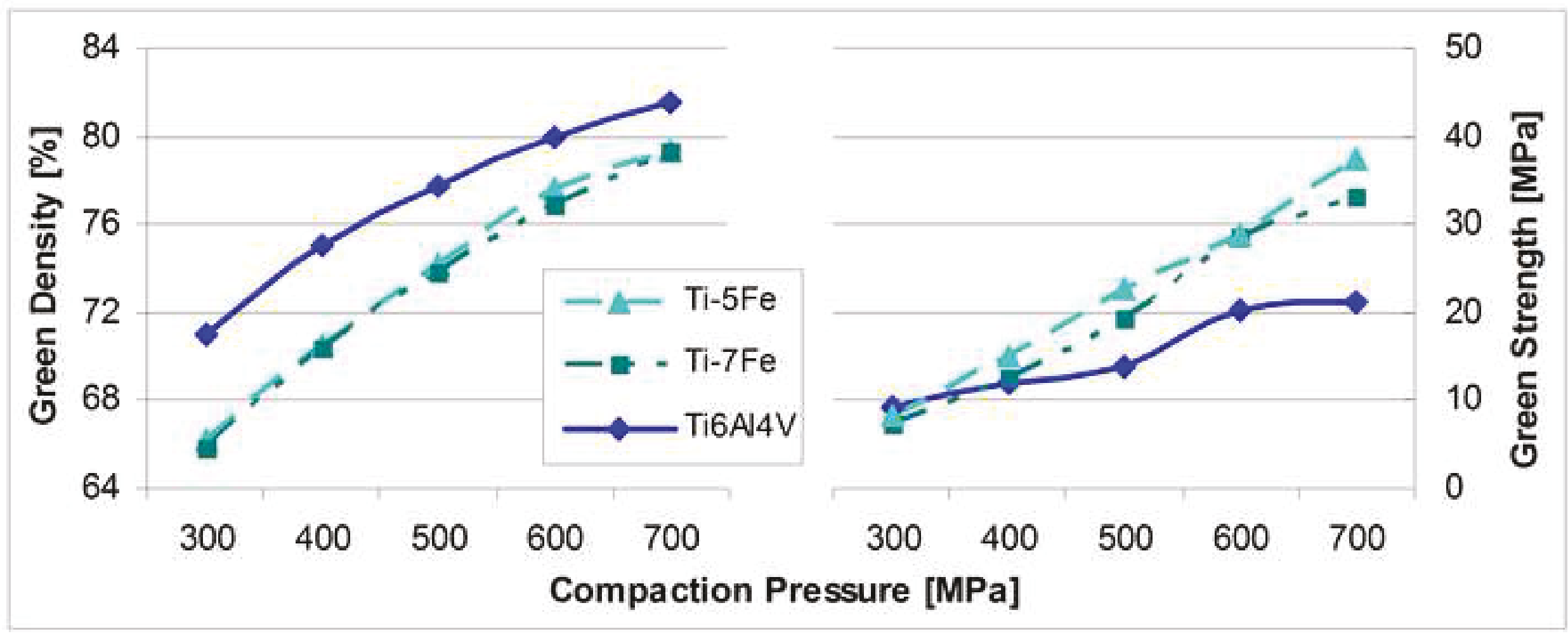




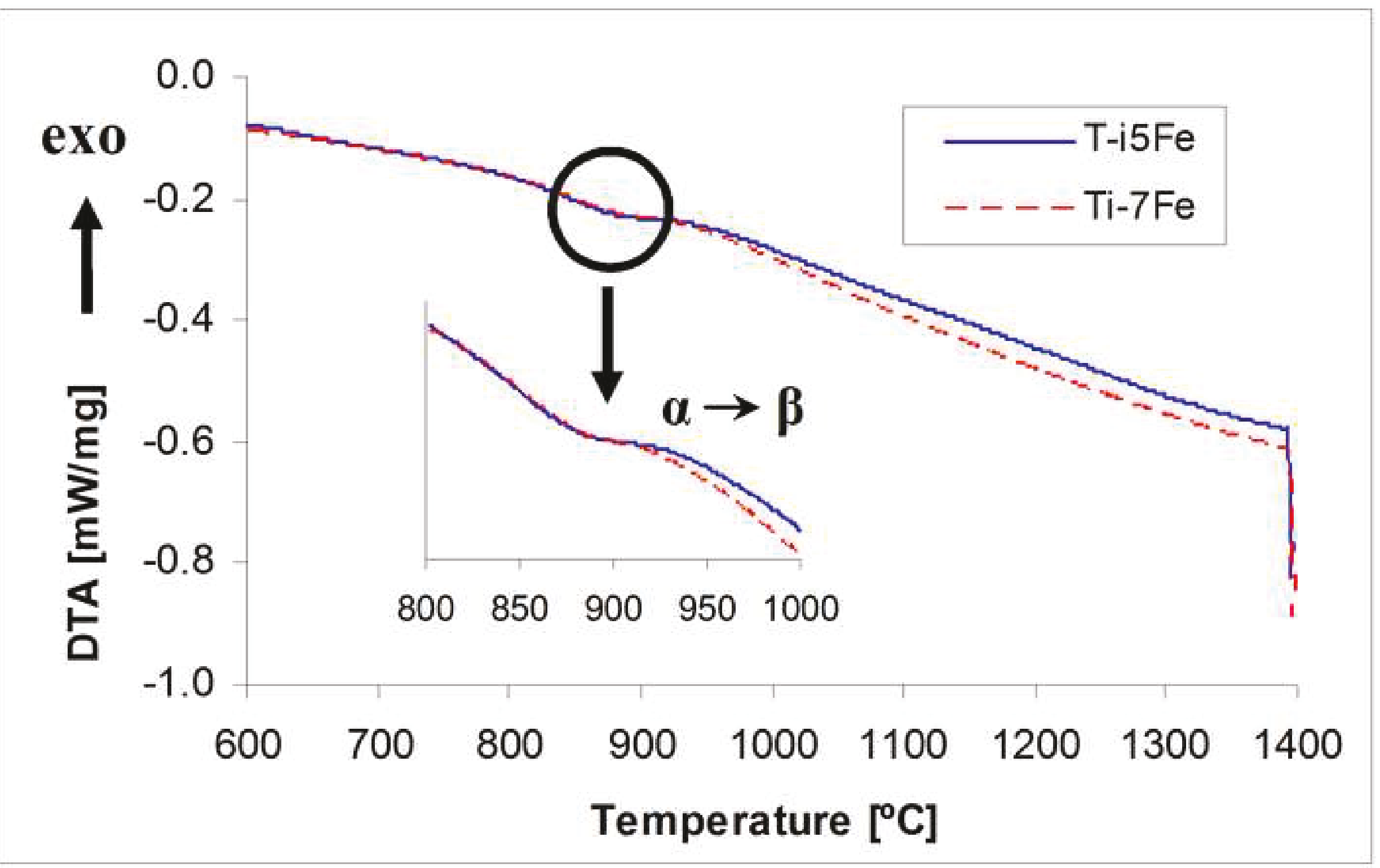




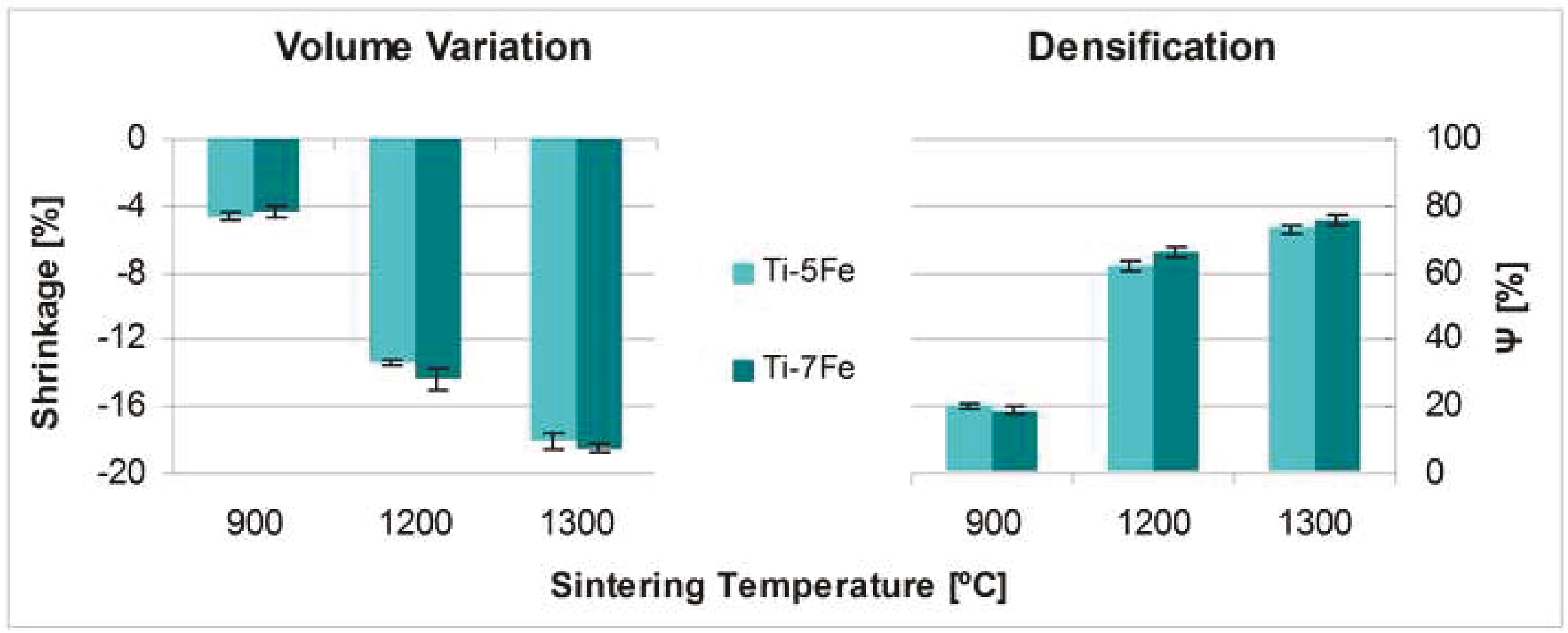


$\square$ Ti-5Fe $\square$ Ti-7Fe $\square$ Ti6A4V

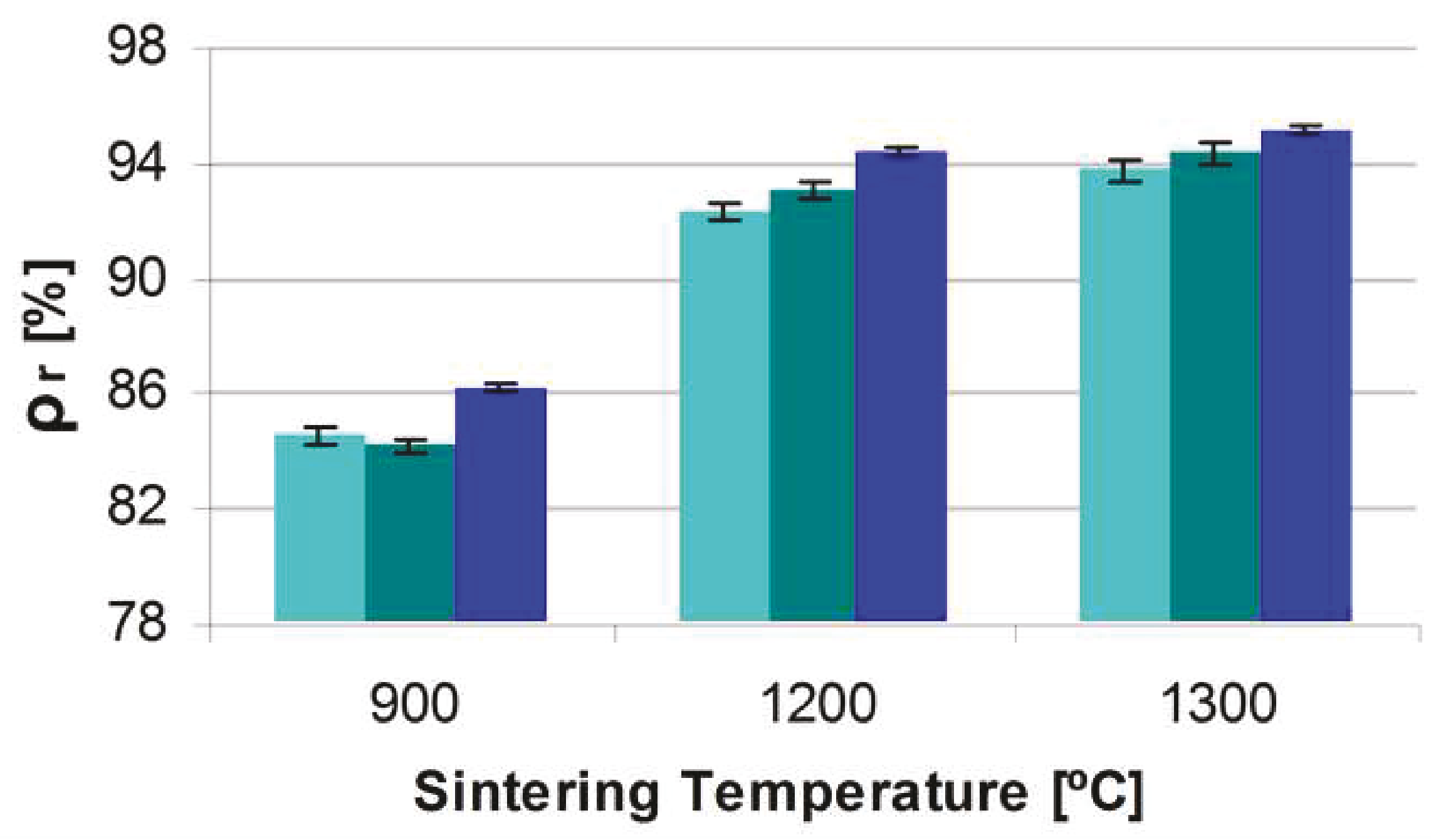


Figure 6
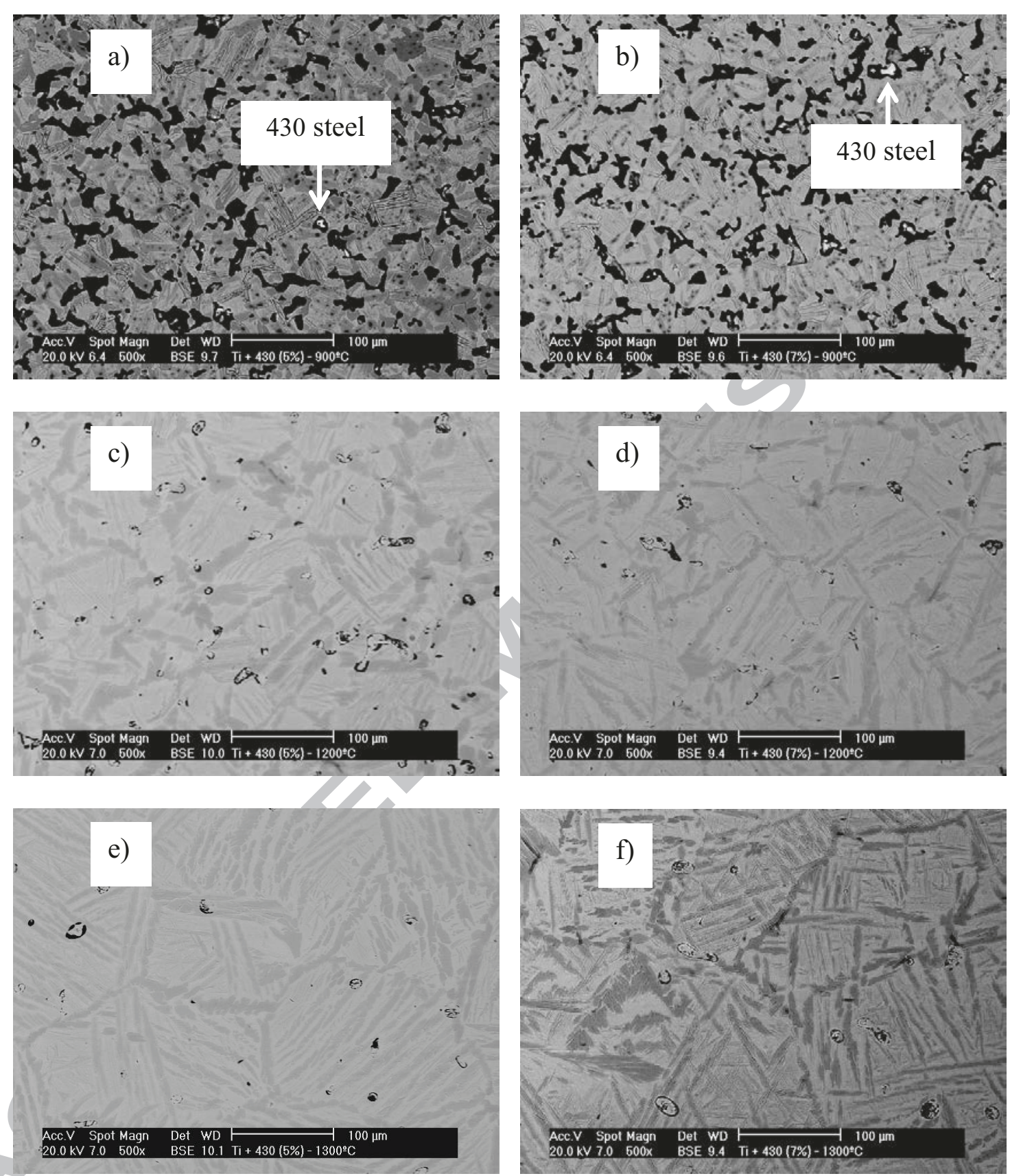
Figure 7

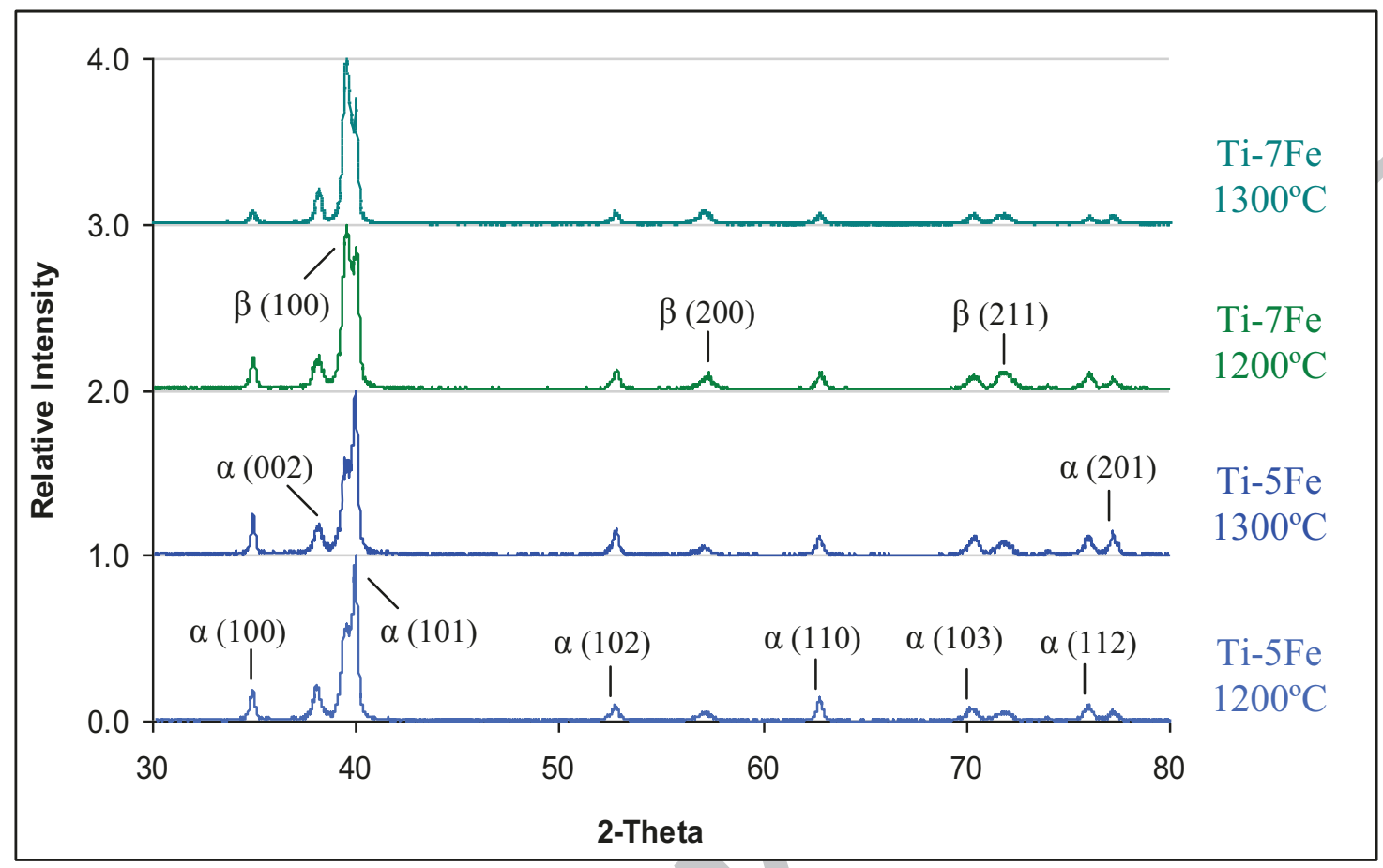




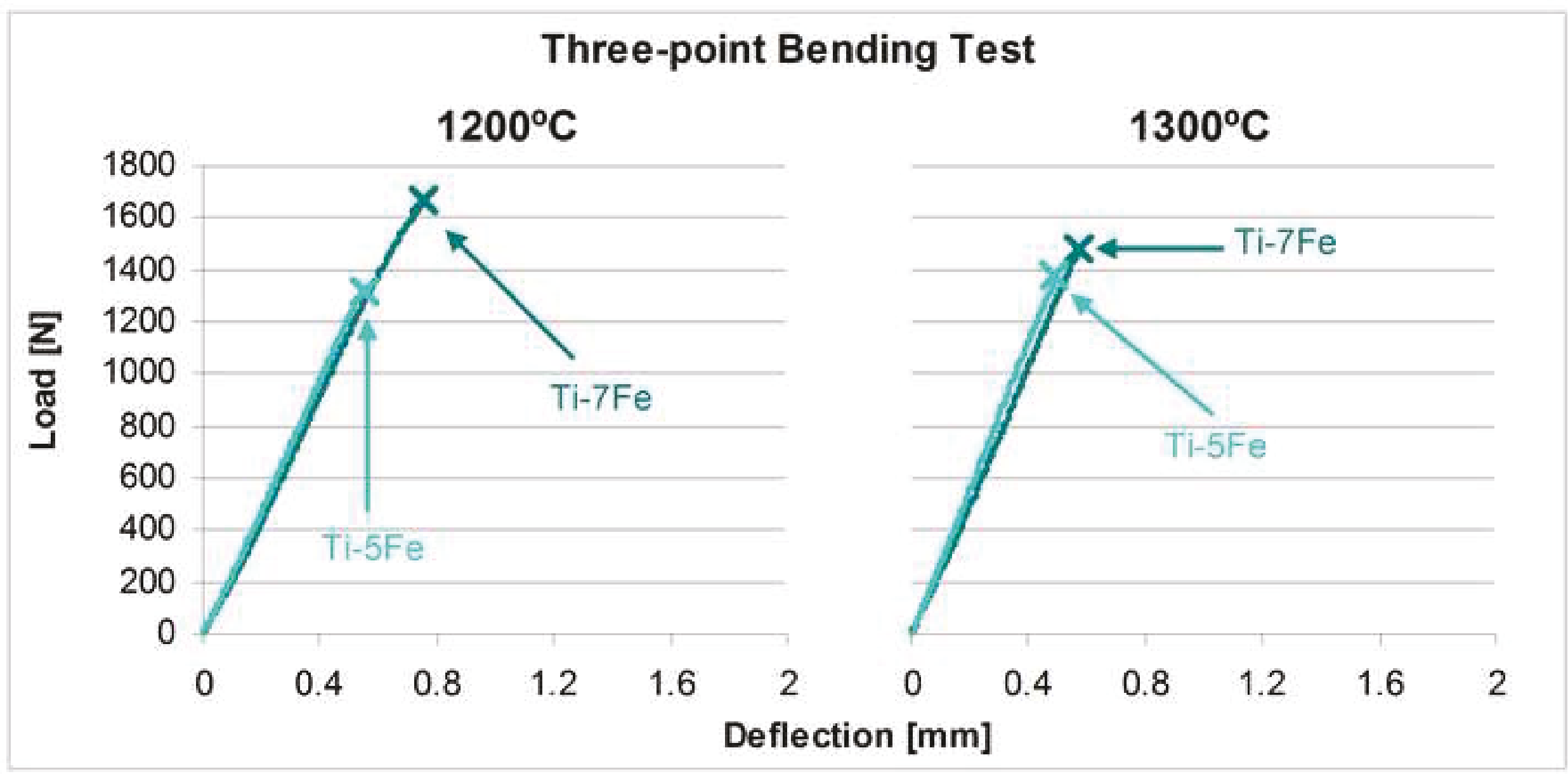




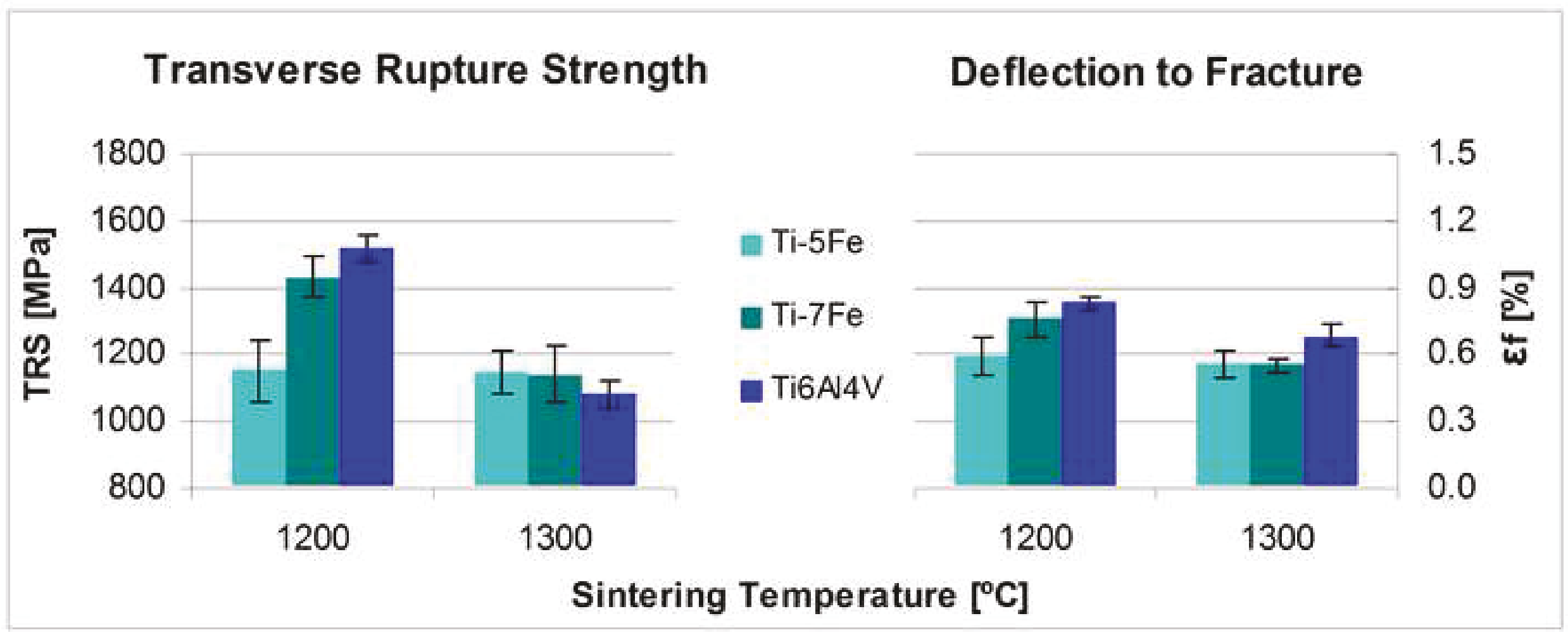


$\square$ Ti-5Fe $\square$ Ti-7Fe $\square$ Ti6Al4V

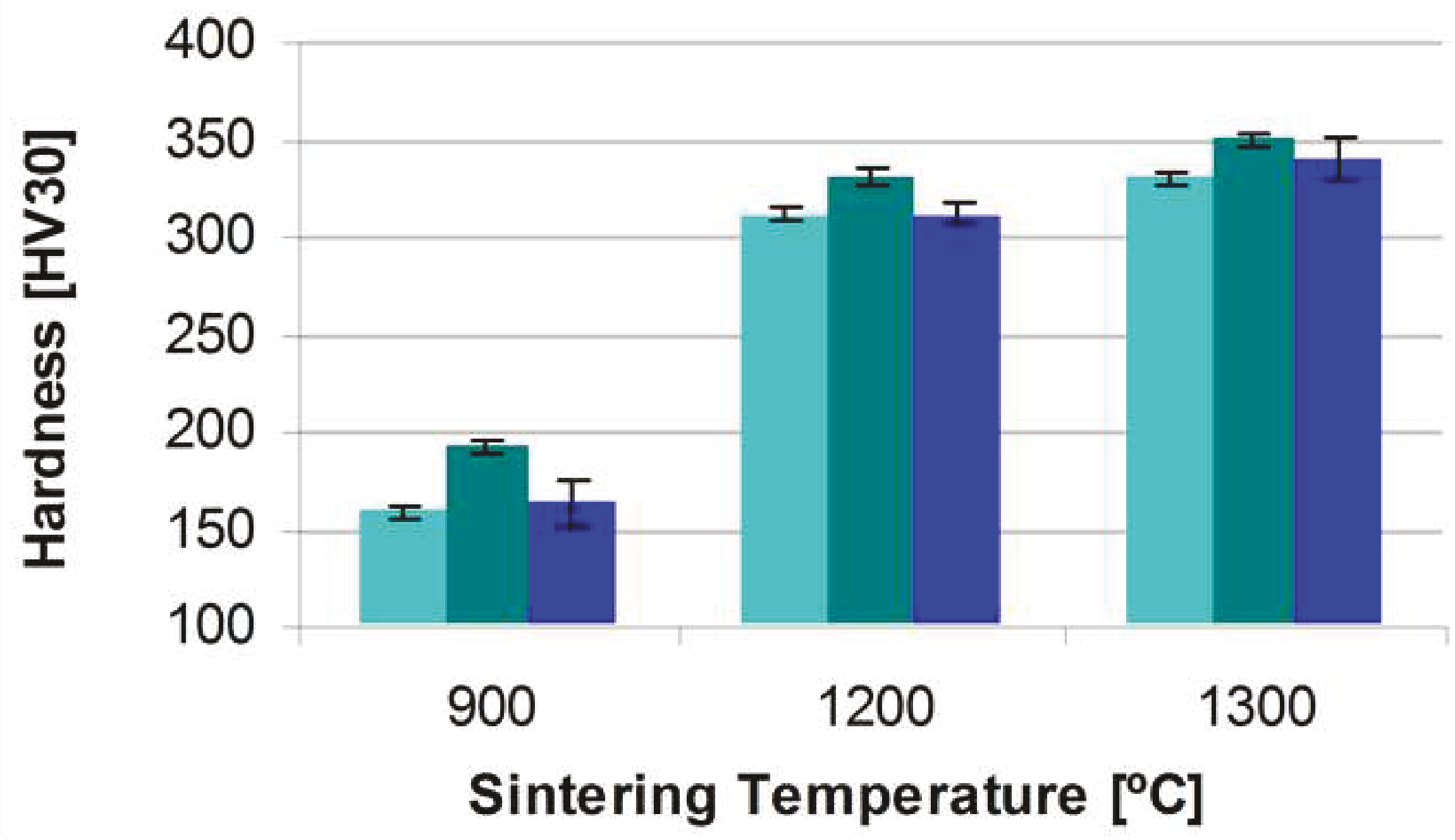

